\section{Presentación del dossier: \\ Encierros y control social. Reflexiones y experiencias encarnadas}

Presentation of the dossier:

Confinements and social control. Reflections and embodied experiences

Berenice Pérez Ramírez; Chloé Constant; Nuria R. Ramírez Solano
RELLGACIÓN

REVISTA DE CIENCIAS SOCIALES Y HUMANIDADES JOURNAL OF SOCIAL SCIENCES AND HUMANITIES REVISTA DE CENCIAS SOCIAIS E HUMANAS

INFORMACIÓN:

http://doi.org/10.46652/rgn.v6i30.877 ISSN $2477-9083$ Vol. 6 No. 30, 2021. e210877 Quito, Ecuador

Enviado: diciembre 15, 2021 Aceptado: diciembre 17, 2021 Publicado: diciembre 22, 2021 Publicación Continua

Sección Dossier | Non Peer Reviewed niñez o para las mujeres sobrevivientes de violencia, los albergues para migrantes, los asilos, entre otros, pueden ser considerados como locus de control y vigilancia, así como espacios complejos para los sujetos en encierro, situándoles entre esquemas de subordinación, sobrevivencia y resistencia, con una gama de experiencias diversas. Constituyen discursos recursivos, instituciones del miedo que justifican el ejercicio de una pedagogía dominante del bien y del mal, de lo bueno y lo malo, son lugares de desecho social. Desde esta perspectiva, las personas encerradas son estudiadas como meros objetos y se silencian sus experiencias, reforzando de esta manera las estructuras que justifican jerarquías, castigos y sistemas de dominación.

Por otro lado, mientras que estos espacios, que configuraban el centro de un modelo social disciplinario (Foucault, 2016; entre otros), viven amplios procesos de transformación, fuera de ellos aumentan los encierros difusos en el marco de la diversificación de modos de control de población, que van desde el terror social provocado con la expansión y espectacularización de la violencia, hasta la aplicación de sofisticados mecanismos electrónicos de vigilancia. Así, tanto el encierro como la vigilancia y el control se vuelven más abarcadores y se normalizan. Un ejemplo de ello, es que, en el contexto de la emergencia sanitaria por Covid-19, el confinamiento se expone como medida "normalizada" para resguardar la vida frente a un entorno de alto riesgo.

Este dossier temático propone compartir reflexiones y experiencias desde el conocimiento situado, buscando resignificar y rearticular (Haraway, 1995)

\section{AUTOR:}

(1) Berenice Pérez Ramírez Universidad Nacional Autónoma de México - México

bereramirez@comunidad.unam.mx

D Chloé Constant

FLACSO México - México chloe.constant@gmail.com

(D) Nuria R. Ramírez Solano Escuela Nacional de Antropología e Historia - México

zintli5o@hotmail.com
ENTIDAD EDITORA 
la relación entre los cuerpos y la investigación vinculada al encierro y el control social. Los artículos presentados en este dossier se enfocan en trabajos realizados con y sobre las personas encerradas y objetos de control social, así como en el análisis de los mecanismos de control social. Las emociones vinculadas al encierro, entendiéndoles como un entramado subjetivo, a la vez que político, constituyen prácticas culturales, relaciones sociales y prácticas corporales; en tanto que uno de los intereses del dossier ha sido comprender las políticas emocionales que se promueven en espacios de encierro y a través de mecanismos de control social, considerando que "[I]a política cultural de las emociones está estrechamente ligada a las historias generalizadas del imperialismo y el capitalismo” (Ahmed, 2015, p. 257).

Hemos intentado conjuntar trabajos que apuesten por nuevos procesos de producción de conocimientos que históricamente no se han considerado como válidos, que emanen especialmente de personas que han experimentado encierro y han estado sujetas a dispositivos de control social. Por otro lado, queremos resaltar ideas y estrategias emancipadoras a partir de ejercicios de intervención, acción e investigación, con el fin de que este dossier abone a contribuciones teórico-prácticas desde y para un diálogo interdisciplinario. Finalmente, nos interesa visibilizar los procesos de exclusión y opresión engendradas en el capitalismo y contextos poscoloniales. Los estudios postcoloniales nos recuerdan que la colonización es un evento histórico mundial de gran magnitud y con rupturas a lo largo del tiempo, en ese sentido, nos permite comprender múltiples relaciones de poder que no encajan dentro de los universales históricos, como pueden ser Estado y nación (Hall, 2013). La cuestión colonial involucra dinámicas de negociación, contención y resistencia, en este sentido surgen dos elementos importantes para pensar lo colonial hasta nuestros días: la articulación de lo económico y lo legal.

En el primer artículo, Martha Vanesa Díaz Padilla aborda la prisionalización y los conflictos del entorno penitenciario en México, mostrando el costo social y económico de la reinserción social. Sostiene que los centros carcelarios, donde se despliega una violencia directa y justificada legalmente, dejan ver una falla en el sistema penitenciario, toda vez que en este entorno se manifiesta una violencia estructural. En el segundo artículo, Pablo Hoyos González se apoya en un análisis genealógico sobre las superposiciones entre el poder disciplinario y la familia burguesa, para argumentar que existe una red de control sobre la familia. Tomando el caso de la prisión, se acerca a las consecuencias del encarcelamiento sobre las mujeres que visitan a internos, con relación a la intensificación de su ocupación productiva y reproductiva. En el tercer artículo, Vanessa Beltrán indaga en las experiencias de enfermedad e internamiento penal de Analía Silva, una mujer afroecuatoriana y cofundadora de la organización Mujeres de Frente (MDF). A través de la reconstrucción etnográfica del proceso de deterioro de su salud, se propone responder ¿Cómo se encarnan los procesos de desposesión y encierro penitenciario en la experiencia de enfermedad de una mujer empobrecida y racializada por el estado penal ecuatoriano? Y, al mismo tiempo, apunta que existen posibilidades de ubicar actos de polítización y resistencia en estos espacios. 
El cuarto artículo, de Inés Mancini, se centra en las redes de afecto y cuidado en las prisiones de Argentina. A través de una metodología cualitativa muestra las tareas de cuidado que despliegan las mujeres hacia varones detenidos, abordando así, cómo se configuran las relaciones de género y evidenciando el trabajo esencial que realizan las mujeres para la supervivencia de los hombres, todo ello, en un contexto de subordinación, violencia institucional y violencia de género. En el quinto artículo, ubicado en el mismo país, María Florencia Actis y Juliana Inés Arens proponen repensar las trayectorias de mujeres que han sido privadas de la libertad a partir de la indagación de los significados que asumen sus estadías carcelarias, intentado desvelar las acciones y decisiones que emprenden para sobrevivir. Apoyadas en la entrevista biográficonarrativa, analizan la relación de las mujeres con las agencias punitivas (no penitenciarias) y con la institución familiar $y$, si bien, se constata que crecen en contextos de pobreza y marginalidad, también se observan estrategias y giros en sus decisiones. En el sexto artículo, Sandra G. Rosas Landa Zamudio e Israel B. Aguillón Cruz describen la Comunidad Terapéutica “Casa de Medio Camino" en Querétaro, México. En este trabajo, se muestran los alcances y las limitaciones en el proceso de inclusión social de pacientes con esquizofrenia y se establecen las diferencias entre rehabilitación, reinserción e inclusión psicosocial. Carmen Gabriela Ruíz Serrano, en el séptimo artículo, nos acerca al estudio de los Centros de Asistencia Social en México, que albergan a niñas, niños y adolescentes que reciben cuidado alternativo. A través de un enfoque metodológico narrativo, documenta cómo estos centros son modelos masificantes de administración de vida y muerte, en tanto existe una cosificación de los y las menores. Luego, contamos con un artículo de Mariana Betzabeth Pelayo Pérez que ubica su propuesta en el contexto de la emergencia sanitaria por COVID-19, donde se reconfiguraron los tiempos, ritmos, procesos de subjetivación, socialización y productividad. Afirma que, con ello, se ha exaltado el terror social y el riesgo pandémico plasmado en discursos, prácticas, imaginarios y deseos.

Finalmente, Rodolfo Bachler Silva, Pablo Segovia-Lagos y Constanza Carter, centrados también en el contexto pandémico pero situados en Chile, se disponen a analizar los grados de rechazo y asimilación que diferentes grupos de personas manifestaron acerca de dos tipos de medidas diseñadas para el control de la pandemia: los confinamientos obligatorios y la modificación de las rutinas diarias. Los resultados les permitieron identificar seis perfiles emocionales asociados a diferentes condiciones sociodemográficas.

\section{Referencias}

Ahmed, S. (2015). La política cultural de las emociones. Programa Universitario de Estudios de GéneroUNAM.

Foucault, M. (2016). La sociedad punitiva. Trad. de Enrique Puchet. Revista Fermentario, 1(10), http:// www.fermentario.fhuce.edu.uy/index.php/fermentario/article/view/243

Hall, S. (2013). Sin garantías: Trayectorias y problemáticas en estudios culturales. Corporación Editora Nacional.

Haraway, D. (1995). Ciencia, cyborgs y mujeres. La reinvención de la naturaleza. Ediciones Cátedra, Universitat de València, Instituto de la Mujer. 


\section{Editoras Invitadas}

Berenice Pérez Ramírez. Doctora en sociología por el Instituto de Ciencias Sociales y Humanidades de la Benemérita Universidad Autónoma de Puebla. Es profesora investigadora en la Escuela Nacional de Trabajo Social de la Universidad Nacional Autónoma de México.

Chloé Constant. Doctora en Sociología-demografía por el Instituto de Altos Estudios de América Latina (Universidad Paris III-Sorbonne Nouvelle). Actualmente es profesora investigadora de la

FLACSO México.

Nuria R. Ramírez Solano. Maestra en Antropología social en la línea de investigación "Antropología del Poder”, del Posgrado en Antropología Social de la Escuela Nacional de Antropología e Historia. Estudiante del doctorado en Antropología social en la ENAH con una investigación sobre mecanismos de control social, securización, criminalización y despojo. 